ORIGINAL ARTICLE

\title{
Low dietary intakes, BMI, iron and aerobic endurance among Sri Lankan professional female hockey players
}

\author{
Ashen Peiris ${ }^{1}$, Pulani Lanerolle ${ }^{1}$, Angela De Silva ${ }^{2}$ \\ ${ }^{1}$ Department of Biochemistry and Molecular Biology, Faculty of Medicine, University of Colombo, Sri Lanka. \\ ${ }^{2}$ Department of Physiology, Faculty of Medicine, University of Colombo, Sri Lanka.
}

\section{Article Information}

Total number of

Words 3118

Tables 01

Figures 03

Authors have no conflicts of interest to declare

Keywords: Low energy intake, Iron deficiency, Low BMI, Aerobic endurance, hockey players

Date of submission: 10.01.2018

Date of acceptance: 03.10 .2018

Author responsible for correspondence: Mr.Ashen Peiris

Spectrum Institute of Science and

Technology, 100, Bauddhaloka Mawatha, Colombo 04, Sri Lanka

Email:ashen@spectrumcampus.edu.lk

http://orcid.org/0000-0002-4806-7525

DOI: http://doi.org/10.4038/cjms. v55i2.4912

\begin{abstract}
Background:

Compromised micronutrient or energy intake can influence body composition which could affect aerobic endurance of athletes potentially resulting in poor performance.
\end{abstract}

Objective:

To study the nutritional status, nutritional intake and aerobic endurance, and to identify potential associations between these parameters in Sri Lankan professional female hockey players.

\section{Method:}

Professional, female hockey players $(n=31)$ were recruited exclusively from professional clubs and the national team. Pretested questionnaires were administered to assess sport specific data and dietary intake. BMI, haemoglobin, serum ferritin and aerobic endurance were assessed.

\section{Results:}

Total energy intake from the diet was less than the individual specific requirement in $52 \%$. Less diversity in carbohydrate intake observed (approximately $1 / 3$ of total energy intake and $1 / 2$ of the carbohydrates, is from rice). Twenty nine per cent were Underweight $\left(\mathrm{BMI}<18.5 \mathrm{~kg} / \mathrm{m}^{2}\right)$. Over half the players were anaemic $(\mathrm{Hb}<120 \mathrm{~g} / \mathrm{L})$ and $25 \%$ were iron deficient (ferritin $<15.00 \mu \mathrm{g} / \mathrm{L}$ ). Dietary intake of iron was less than the Recommended Dietary Allowance $(<18 \mathrm{mg} /$ day) in $90 \%$. Mean aerobic endurance $\left(27.98 \pm 6.90 \mathrm{~mL} / \mathrm{min} / \mathrm{kg}\right.$ ) (maximal oxygen uptake, $\left.\mathrm{VO}_{2} \max \right)$ was very low. A moderate negative correlation $(\mathrm{r}=-0.672)(\mathrm{P}<0.01)$ for BMI and a moderate positive correlation $(\mathrm{r}=+0.538)(\mathrm{P}<0.01)$ for energy balance were observed for $\mathrm{VO}_{2}$ Max.

\section{Conclusions:}

Inadequate and less diverse dietary intakes, low BMI and iron deficiency were observed in this cohort of professional hockey players. Observed low aerobic endurance levels in these athletes is a concern for performance and the nutritional factors that coexist may have played a part. Education on the concept of optimum nutrition for performance in these individuals is warranted.

\section{Background}

Baseline analysis and interventions in nutrition are potential key contributing factors in improving sports performance through its contribution to the improvement of body mass, body composition, nutritional intake and aerobic capacity $[1,2]$.
Studies covering professional Sri Lankan athletes are sparse, especially hockey players. The present study should contribute in devising performance enhancing protocols in the future for hockey players in Sri Lanka.

Chronic inadequate energy intake can result in loss of body mass, loss of muscle mass, loss/ failure to gain 
bone density, increased risk of fatigue and injury, prolonged recovery periods from sporting activity, menstrual dysfunction, increased risk of illness[2]. Generally female athletes have shown lesser energy intakes than the specific requirements compared to male athletes[3]. A physically active female, aged 19-30, requires an energy intake of approximately 10048 kJ/day[4]. Carbohydrates 55-67\%, lipids 20$35 \%$ and proteins $10-13 \%$ of daily energy intake in general is recommended for athletes with a higher end carbohydrate intake for endurance sports such as hockey[2]. Body mass index (BMI) provides a good indicator of chronic energy deficiency. Chronic malnutrition with inadequate macro and micro nutrients and a negative energy balance results in weight loss[5]. Individuals with a BMI below $18.5 \mathrm{~kg} / \mathrm{m}^{2}$ are considered underweight and malnourished[6].

A deficit in prolonged, overall energy intake due to low consumption of food, micronutrient intake could be compromised and could lead to iron deficiency in athletes[7]. Recommended dietary allowance (RDA) for iron is $18 \mathrm{mg} /$ day for premenopausal women[8]. An increment of 30-70\% of daily iron intakes for endurance athletes is recommended, especially for female athletes[9]. Physically active females are found to be more susceptible to iron deficiency compared to males and sedentary females. The main contributors to iron deficiency in females are iron loss via menstrual blood and inadequate dietary iron intake[10]. The recommended haemoglobin concentration for adult females is $\geq 120 \mathrm{~g} / \mathrm{L}$ and, lesser values are indicative of anaemia[11]. A serum ferritin concentration $<15$ $\mu \mathrm{g} / \mathrm{L}$ indicates iron deficiency in adult females and persistent iron deficiency leads to iron deficiency anaemia, most prevalent form of anaemia worldwide[10, 11]. In early iron deficiency energy generating metabolic pathways could be interrupted as iron has a vital role as enzyme co-factors, reducing the rate of oxygen consumption and reducing aerobic capacity[12]. Further progression of iron deficiency leads to anaemia, reducing oxygen transportation capacity, further reducing the rate of oxygen consumption and reducing aerobic capacity[13]. Maximum aerobic capacity is the maximum amount of oxygen the body can utilize within a unit time per kilogram of body weight $\left(\mathrm{VO}_{2}\right.$ max). This defines an upper limit to the maximum work rate that can be sustained aerobically[14]. Hockey is considered to be a physiologically highly demanding sport with frequent intermittent efforts requiring rapid recovery, making aerobic fitness essential in maintaining sports performance[15]. Maximum aerobic capacity of competitive female hockey players are generally observed to be in the range between $45-59 \mathrm{~mL} / \mathrm{min} / \mathrm{kg}[1]$.

\section{Objectives}

To study the nutritional status, nutritional intake and aerobic endurance, and to identify potential associations between these parameters in Sri Lankan professional female hockey players.

\section{Methods}

\section{Subjects}

A cross sectional study was conducted in a purposive sample of volunteered female field hockey players $(n=31)$. All volunteers were contracted athletes from Sri Lankan armed forces, encamped in Central Province and Western Province. This was a sub group of a total of approximately 50 female field hockey players at professional level in Sri Lanka, engaged full-time in hockey without any additional duties. Participants regularly engaged in practice sessions for approximately 2 times a day, 6 days per week as well as in regular competitions. Subjects were aged between 18-32 years, presently competing at international level and/or national level. Recruitment of subjects took place during a non-vacation period to ensure the participants involvement in regular training and competition. Subjects with major illnesses or major injuries within a year of the time of recruitment were excluded. Ethical clearance for the study was obtained from the Ethics Review Committee, Faculty of Medicine, University of Colombo. Prior, informed written consent was obtained from all the participants.

Data collection was done on reserved dates where the participants were not involved in any form of training or competition. Height and weight of the participants were initially measured using standard protocol. A blood sample was collected from each participant following standard aseptic procedure. One hour post blood collection, participants were subjected to a 20 meter shuttle run test (beep test) as a proxy for measuring $\mathrm{VO}_{2}$ max. General information, sport related information, general health related information was obtained using a pre tested interviewer administered general questionnaire. Data on dietary intakes were obtained using an interviewer administered 24 hour dietary recall questionnaire. Laboratory analysis of the blood samples was carried out at the Department of Biochemistry and Molecular Biology, Faculty of Medicine, University of Colombo.

\section{Blood sample collection and analysis}

Blood samples were obtained between 8.00-10.00 am from the median cubital vein, using a 21 gauge syringe. Use of tourniquet was kept to a minimum in order to reduce haemolysis. Required volumes of blood were dispensed into EDTA tubes and serum separation tubes. The samples were immediately stored at $4^{\circ} \mathrm{C}$ temporarily and transported. On the same day, haemoglobin was spectrophotometrically analyzed (UV-1601, Shimadzu, Japan) using Cyanmethemoglobin method [16]. Serum was aliquoted and stored at $-20^{\circ} \mathrm{C}$ for laboratory analysis. Within a period of two weeks from the date of sample collection serum ferritin was analysed using an ELISA kit (Diagnostic automation, USA) and a microtiter plate reader (Multiskan EX, Thermo, USA). 


\section{Anthropometric measurements and calculating specific energy requirements}

Height and weight (Seca, Germany) of each participant were measured using standard protocol, in their regular training attire, without shoes, protective gear and hair accessories. Body mass index (BMI) was calculated.

Anthropometric data was used to calculate individual specific energy requirements using the modified Harris-Benedict equation[17].

\section{VO, max assessment}

Twenty meter shuttle run test (beep test) was carried out. A standard regression equation was used to indirectly calculate $\mathrm{VO}_{2}$ max (maximum aerobic capacity)[18]. The test was carried out between 9.00-11.00 am, in batches of 7-10 participants each. An even, outdoor, grass covered surface with moderate to low sunlight was used for the test.

\section{Questionnaires}

General information regarding, time commitment to hockey, recent injuries and illnesses, recent history of dietary supplementation and medications were obtained from each participant through a pre-tested interviewer administered, questionnaire.

Information regarding the types and quantities of food consumed and dietary supplementation were obtained through an interviewer administered, 24-hour dietary recall questionnaire. Obtained information was carefully scrutinized with the participants to identify deviations in the recorded data from the regular consumptions and was adjusted accordingly. In order of priority information on food packages, standard food composition tables issued by World Health Foundation of Sri Lanka and National Nutrient Database for Standard Reference, USA were used to identify nutritional composition $[19,20]$. Accordingly total daily energy intakes, energy intakes from each type of macronutrient and daily intakes of iron were calculated.

\section{Statistical analysis}

Data were analysed using the Statistical Package for Social Sciences (SPSS) software (version 20.0). Anthropometric data, iron status and dietary intakes were categorized based on American Dietetic Association, Institute of Medicine (USA) and World Health Organization recommendations/ cut-off values. Normality of data distributions was assessed using the Shapiro-Wilks test. Independent sample t-test was used to analyse significant differences between groups (underweight vs normal weight, inadequate micronutrient status vs adequate micronutrient status, inadequate energy consumers vs adequate energy consumers, national level players vs international level players, differences according to playing positions). Bivariate analysis using Pearson and Spearman co-efficients were used to analyse correlations between variables (BMI, iron status, $\mathrm{VO}_{2}$ max, dietary intakes).

\section{Results}

\section{Energy intake and BMI}

A mean energy intake of $9585 \pm 2085 \mathrm{~kJ} /$ day was observed in the participants. When individually calculated, a mean energy requirement of $9277 \pm 572$ $\mathrm{kJ} /$ day was observed. A majority of $52 \%$ of the participants had energy intake values lesser than the individual specific daily requirement (negative energy balance).

A considerable amount of rice consumption was observed among the participants (average of $242 \pm 100 \mathrm{~g} /$ day raw weight). On average, approximately $1 / 3$ of total energy intake and almost $1 / 2$ of the carbohydrate requirement was obtained from rice (Table 1$)$.

Table 1. Major contributors in total daily energy intakes of participants.

\begin{tabular}{lcccc}
\hline & $\begin{array}{c}\text { Number of } \\
\text { participants } \\
\text { consumed } \\
\text { the food (n) }\end{array}$ & $\begin{array}{c}\text { Estimated Estimated } \\
\text { mean } \\
\text { daily } \\
\text { intake } \\
\text { mean } \\
\text { energy }\end{array}$ & $\begin{array}{c}\text { Mean \% of } \\
\text { food } \\
\text { contribution } \\
\text { to total } \\
\text { energy } \\
\text { intake }\end{array}$ \\
\hline Rice & 31 & $242 \pm 10 \mathrm{~g}$ & $\begin{array}{c}3507 \pm 1448 \\
\mathrm{~kJ}\end{array}$ & $36 \pm 15 \%$ \\
Dhal & 28 & $56 \pm 32 \mathrm{~g}$ & $\begin{array}{c}785 \pm 107 \\
\mathrm{~kJ} \\
904 \pm 347 \\
\mathrm{~kJ}\end{array}$ & $8 \pm 1 \%$ \\
Chickpea & 4 & $60 \pm 23 \mathrm{~g}$ & $9 \pm 3 \%$ \\
\hline
\end{tabular}

The mean BMI of participants was $20.3 \pm 3.1 \mathrm{~kg} / \mathrm{m}^{2}$. One third of participants $(29 \%)$ were underweight $\left(<18.5 \mathrm{~kg} / \mathrm{m}^{2}\right)$. Two were severely underweight $\left(<16.00 \mathrm{~kg} / \mathrm{m}^{2}\right)$ and further three were moderately underweight $\left(16.00-16.99 \mathrm{~kg} / \mathrm{m}^{2}\right)$.

No significant difference in energy intake was observed $(\mathrm{P}=.52)$ between the underweight individuals ( $9963 \pm 1649 \mathrm{~kJ} /$ day $)$ and individuals with $\geq 18.5 \mathrm{~kg} / \mathrm{m}^{2}$ BMI $(9422 \pm 2218 \mathrm{~kJ} /$ day $)$. Comparison between individuals with a positive energy balance and negative energy balance, significant differences could not be observed in haemoglobin (122.47 \pm 9.85 $\mathrm{g} / \mathrm{L}$ against $116.31 \pm 9.03 \mathrm{~g} / \mathrm{L})(\mathrm{P}=.08)$ and ferritin $(31.33 \pm 22.22 \mu \mathrm{g} / \mathrm{L}$ against $31.31 \pm 20.29 \mu \mathrm{g} / \mathrm{L})$ $(\mathrm{P}=.99)$.

\section{Iron status and iron intake}

More than half the study population (55\%) had low haemoglobin $(<120 \mathrm{~g} / \mathrm{L})$. This included five who were moderately anaemic $(80.00-109.99 \mathrm{~g} / \mathrm{L})$. A quarter of participants $(26 \%, \mathrm{n}=08)$ had serum ferritin levels below the cut-off value $(<15.00 \mu \mathrm{g} / \mathrm{L})$. No significant difference was observed $(\mathrm{P}=.93)$ between the serum ferritin concentrations of anaemic individuals $(\mathrm{Hb}<120 \mathrm{~g} / \mathrm{L})(29.78 \pm 19.54 \mu \mathrm{g} / \mathrm{L})$ and non-anaemic individuals $(33.46 \pm 23.26 \mu \mathrm{g} / \mathrm{L})$. A 
significantly lower $(\mathrm{P}=.03) \mathrm{BMI}\left(18.64 \pm 1.80 \mathrm{~kg} / \mathrm{m}^{2}\right)$ was observed in individuals with depleted serum ferritin $(<15.00 \mu \mathrm{g} / \mathrm{L})$ compared to the individuals with adequate serum ferritin concentrations $\left(20.84 \pm 3.29 \mathrm{~kg} / \mathrm{m}^{2}\right)$.

Iron intakes of $11.34 \pm 3.99 \mathrm{mg} /$ day, range 2.80 $19.50 \mathrm{mg} /$ day was observed in the participants. A considerable number of participants $(90 \%)$ had inadequate iron intakes ( $<18 \mathrm{mg} /$ day) (Figure 1). An aggregate of $79 \%$ of total iron intakes of the cohort were recorded from plant based sources, $12 \%$ animal sources and $9 \%$ fortified food. No significant difference was observed between the daily iron intake of individuals with positive calorie balance $(12.1 \pm 3.8 \mathrm{mg} /$ day $)$ and negative calorie balance $(10.6 \pm 4.1 \mathrm{mg} /$ day $) \quad(\mathrm{P}=.32)$, anaemic individuals $(11.7 \pm 3.9 \mathrm{mg} /$ day) and non-anaemic individuals ( $10.8 \pm 4.2 \mathrm{mg} /$ day) $(\mathrm{P}=.62)$, individuals with adequate serum ferritin $(11.9 \pm 3.9 \mathrm{mg} /$ day $)$ and inadequate serum ferritin $(9.8 \pm 4.3 \mathrm{mg} /$ day $)(\mathrm{P}=.22)$.

Figure 1. Daily iron intake of participants. Recommended dietary allowance (RDA) for iron is $18 \mathrm{mg}$ per day for pre-menopausal women [8]. An increment of 30-70\% of daily iron intakes for endurance athletes is recommended, especially for female athletes [9]

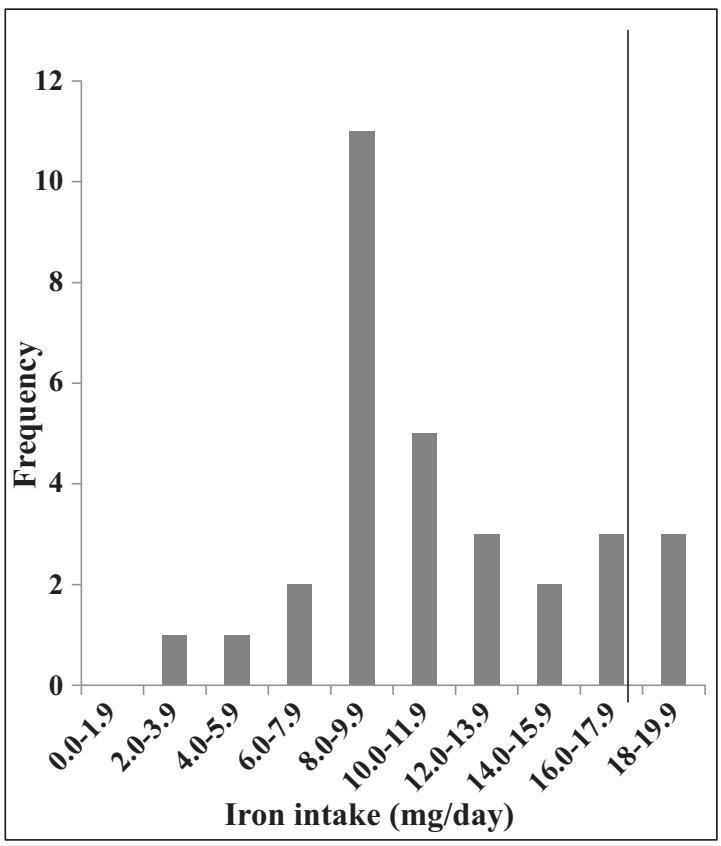

\section{Aerobic endurance}

A mean $\mathrm{VO}_{2}$ max value of $27.98 \pm 6.90 \mathrm{~mL} / \mathrm{min} / \mathrm{kg}$ and a range of $15.97-41.79 \mathrm{~mL} / \mathrm{min} / \mathrm{kg}$ was observed in the participants. All individuals have shown lesser $\mathrm{VO}_{2}$ max values compared to generally observed values in female hockey players $(45-59 \mathrm{~mL} / \mathrm{min} / \mathrm{kg})$.

No significant difference was observed $(\mathrm{P}=.99)$ between the $\mathrm{VO}_{2}$ max values of non-anaemic $(28.00 \pm 6.94 \mathrm{~mL} / \mathrm{min} / \mathrm{kg})$ and anaemic $(27.96 \pm 7.07$
$\mathrm{mL} / \mathrm{min} / \mathrm{kg}$ ) individuals. With $\mathrm{VO}$ max, a moderate negative correlation $(\mathrm{r}=-0.672)(\mathrm{P}<.001)$ for $\mathrm{BMI}$ (Figure 2) and a moderate positive correlation $(\mathrm{r}=+0.538)(\mathrm{P}<.002)$ for energy balance (deficit/ surplus) was observed (Figure 3).

Figure 2. Moderate negative correlation observed between BMI and aerobic capacity $\left(\mathrm{VO}_{2} \max \right)(\mathrm{r}=-$ 0.672) $(\mathrm{P}<.001)$.

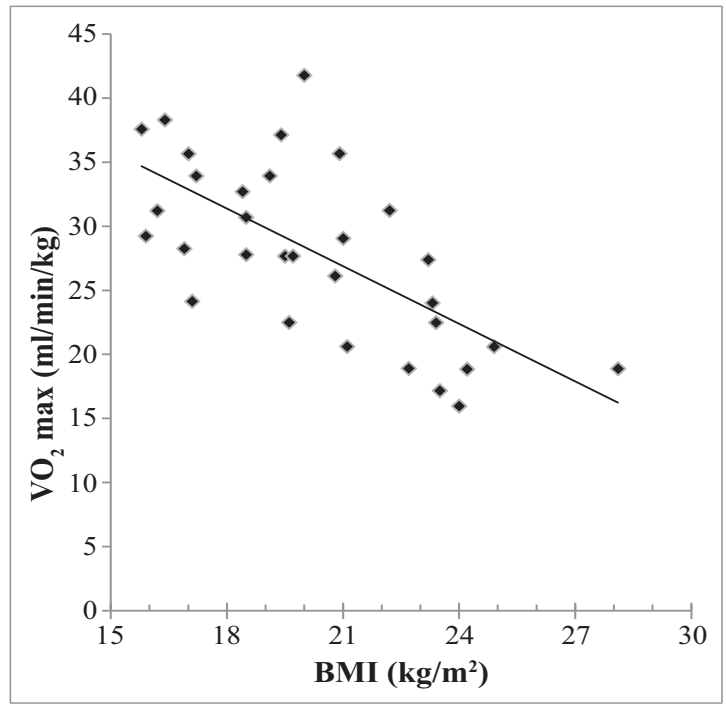

Figure 3. Moderate positive correlation observed between energy balance and aerobic capacity $\left(\mathrm{VO}_{2} \max \right)(\mathrm{r}=+0.538)(\mathrm{P}=002)$.

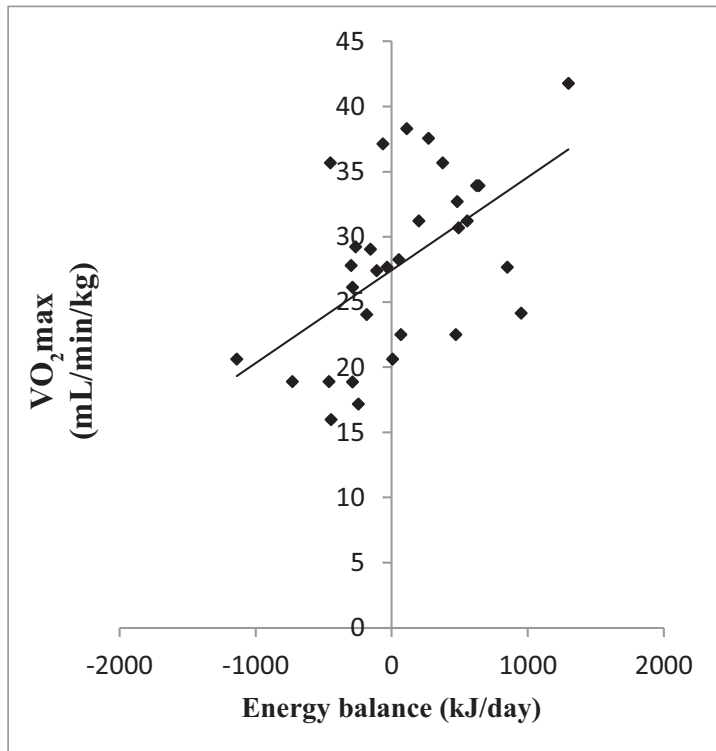

Playing positions and playing level related results

The study in total consisted of $n=20$ international level and $n=11$ national level players. Based on the primary playing positions 15 were attackers, nine were midfielders, four were defenders, and three were goal keepers. No significant difference was observed between the international level players 
and the national level players regarding $\mathrm{VO}_{2} \max$ values and tested nutritional parameters. Goal keepers have shown significantly lower $(\mathrm{P}<.003)$ $\mathrm{VO}_{2}$ max values $(17.35 \pm 1.47 \mathrm{~mL} / \mathrm{min} / \mathrm{kg})$ compared to outfield players $(29.12 \pm 6.23 \mathrm{~mL} / \mathrm{min} / \mathrm{kg})$. Goal keepers have shown a significantly higher BMI $\left(25.21 \pm 2.51 \mathrm{~kg} / \mathrm{m}^{2}\right)$ compared to midfielders $(18.56$ $\left.\pm 2.55 \mathrm{~kg} / \mathrm{m}^{2}\right)(\mathrm{P}<.003)$ and forwards $(20.21 \pm 1.47$ $\left.\mathrm{kg} / \mathrm{m}^{2}\right)(\mathrm{P}<.004)$.

\section{Discussion}

\section{Low energy intake, lack of dietary diversity and} low body mass index

During the study period, dietary intakes of the athletes were not monitored and no specialized dietary protocols were in place. With an estimated energy expenditure of $35.6-50.2 \mathrm{~kJ} /$ minute, field hockey is considered as a 'heavy exercise' sport having high energy requirements [1]. A constant training schedule of two training sessions per day, 5-6 days per week as reported by the participants puts a considerable energy requirement on the athletes. Overall, low daily energy intake observed in majority of the participants $(52 \%)$ is a major concern.

Adiversified, high carbohydrate diet is recommended for endurance in athletes to fulfil the extra carbohydrate and micronutrient requirements[21]. Considering the tendency demonstrated in the study, participants to depend mostly on a food source such as rice to fulfil a larger quota of their energy requirement (approximately $1 / 3$ of total energy intake) and carbohydrate requirements (approximately 1/2 of carbohydrate intake) there is lack of dietary diversification, which might lead to poor nutrition related outcomes concerning the long term health of these athletes.

A low BMI is generally associated with chronic malnutrition, anaemia and poor musculoskeletal status[22]. However, the present study failed to show a positive association between energy intake and BMI. The single 24-hour dietary recall may not have reflected the deficits in long term dietary habits of individuals. However, as iron deficient individuals have shown significantly lower BMI values than non-iron deficient individuals, indicating the presence of chronic malnutrition and its potential association with compromised micronutrient status. Recent changes to dietary habits might not have been reflected in the study as energy balance did not associate with BMI and iron status. The higher prevalence of low energy intake and low BMI in the same population is an important factor to note.

Steps should be taken to increase energy intake and increase dietary diversity. The dependence on a single 24-hour dietary assessment protocol which is sensitive to daily dietary intake variations is a limitation of the present study. A long term dietary assessment is required to assess the dietary habits of the cohort which is likely to produce more accurate and reliable results. Further measures should be taken to monitor players' body weight, body composition throughout the season and off-season period in order to identify the requirement of interventions.

\section{Low iron status and low iron intake}

Anaemia was prevalent in more than half of the cohort and an even greater number of participants could be at risk of inadequate iron status. The standard WHO cut-off value for haemoglobin $(120 \mathrm{~g} / \mathrm{L}$ for adult females) is for non-athletic populations. There could be an increased requirement of haemoglobin in the participants due to increased physical activity. Studies have shown an increment in haemoglobin values of non-anaemic and mildly anaemic athletes following iron supplementation[23, 24]. It is important to take adequate measures aimed at reducing anaemia in athletes, especially in those from developing countries such as Sri Lanka.

Reduced iron stores assessed through low serum ferritin levels $(<15.00 \mu \mathrm{g} / \mathrm{L})$ indicate early stages of iron deficiency. Iron deficiency is prevalent in the cohort with $>20 \%$ individuals having low serum ferritin[11]. In athletes, some studies have shown positive associations with improved performance outcomes and improvements in iron status following iron supplementation, using higher serum ferritin cut-off values (up to $20 \mu \mathrm{g} / \mathrm{L}$ ) suggesting the use of a higher cut-off value for athletes[10, 25].

Absence of an association was observed between anaemia $(\mathrm{Hb}<120 \mathrm{~g} / \mathrm{L})$ and depleted iron stores (ferritin $<15.00 \mu \mathrm{g} / \mathrm{L}$ ). This suggests the presence of other micronutrient deficiencies (folic acid and vitamin A) apart from iron deficiency, impairing haemoglobin synthesis and should be investigated further[26]. Serum ferritin levels could be elevated due to exercise induced inflammation and infection $[10,11]$. However, at the time of the study no athlete reported having illnesses either during or in the past two weeks, reducing this possibility. In order to obtain a more accurate assessment of iron stores it is recommended to assess other markers such as soluble transferrin receptor levels, C-reactive protein coupled with serum ferritin[27].

Overall, majority of the participants (90\%) had inadequate iron intakes ( $<18 \mathrm{mg} /$ day) and a large proportion of iron intakes were from plant based sources (79\%)[8]. Anti-nutritional factors such as phytates, tannins and polyphenols present in plants are known to reduce iron bioavailability, reducing iron absorption[28]. It is likely that the iron requirement of most of the individuals was not met by dietary sources and none were on iron supplementation. Increasing the dietary iron intake, addressing bioavailability and including supplementation can be recommended for this population.

No associations were observed between iron intakes, iron status and aerobic endurance. Markers used for 
assessment of iron status were haemoglobin and serum ferritin. The first can be reduced by other micronutrient deficiencies[26] and serum ferritin can be elevated due to infection and exercise induced inflammation[10, 11]. Single 24 hour dietary recall may not have reflected the long term iron intakes. These factors might have affected the establishment of associations between iron intakes, iron status and aerobic endurance in the present study. Maintaining proper iron status is in itself an important factor from an athlete's perspective for proper functionality of energy generating metabolic pathways and the transportation of oxygen to the working compartments of the body[10, 11]. Low iron intake and poor iron status with prevalent anaemia and iron deficiency in the same population is noteworthy.

\section{Low aerobic endurance}

At the time of the study a properly regulated training regime to improve physical attributes of the athletes was not in place. Given the average maximum aerobic capacity of competitive female hockey players to range approximately between $45-59 \mathrm{~mL} / \mathrm{min} /$ $\mathrm{kg}$ of oxygen, $\mathrm{VO}_{2}$ max values shown in the study $(27.98 \pm 6.90 \mathrm{~mL} / \mathrm{min} / \mathrm{kg})$ points towards a major deficit in aerobic capacity of Sri Lankan, female field hockey players[1]. Despite not observing direct associations in the present study due to potential confounding factors, the prevalence of poor iron intakes, iron status and aerobic endurance in the same population is noteworthy. This is suggestive of presence of poor nutritional status and poor aerobic capacity which can lead to poor performance in sports. With $\mathrm{VO}_{2}$ max, the positive correlation of energy balance and negative correlation of BMI are suggestive of the importance of maintaining daily energy balance and body composition. Past studies have shown positive associations between fat free mass and aerobic capacity[29]. Further studies should be carried out in investigating the effect of energy balance, BMI and body composition on aerobic capacity for the specific population and to implement programs aimed at improving aerobic endurance of the participants.

\section{Indiscriminate features between national level and international level players}

No specialized long term training or nutritional programs for players competing at international level were observed to be present at the time of study. Lack of significantly higher aerobic endurance and nutritional parameters in international level athletes emphasize the requirement for implementing specialized programs for such athletes competing at higher competitive levels.

Significant differences were observed in BMI and aerobic capacities of groups of participants playing at different positions (goal keepers from outfield players). This should be investigated further with relevance to their different on-field requirements.

\section{Conclusion}

This study identifies deficits in energy intakes, body weight, iron intake and iron status; a collective influence of such factors may have led to very low aerobic endurance levels in the participants. Regularly monitored, individualized dietary and training programs must be prioritized for professional athletes in developing countries aimed at improving nutritional status, body mass and body composition.

\section{Acknowledgment}

We appreciate the assistance provided by $\mathrm{Mr}$. J. Weerasinghe, Mr. T. Andrahennadhi, Mr. S. Kolambage at the Department of Biochemistry and Molecular Biology, Faculty of Medicine, University of Colombo and commitment of study participants.

\section{Competing interests}

There are no competing interests to report regarding this study.

\section{Funding}

Funding was provided by the Department of Biochemistry and Molecular Biology, Faculty of Medicine, University of Colombo.

\section{References}

1. Reilly T, Borrie A. Physiology applied to field hockey. Sports Med. 1992;14(1):10-26.

2. American Dietetic Association. Dietitians of Canada; American College of Sports Medicine, Rodriguez NR, Di Marco NM, Langley S.: American College of Sports Medicine position stand. Nutrition and athletic performance. Med Sci Sports Exerc. 2009;41(3):709-31.

3. Bernad AL, Garcia-Galbis MR. Energy and macronutrient intake in female athletes. Nutr Hosp. 2015;32(5):1936-48.doi: 10.3305/ nh.2015.32.5.9280.

4. Institute of Medicine. Dietary Reference Intakes for Energy, Carbohydrate, Fiber, Fat, Fatty Acids, Cholesterol, Protein and Amino Acids. 1st ed. Washington (DC): The National Academic Press; 2005.

5. Kurpad AV, Muthayya S, Vaz M. Consequences of inadequate food energy and negative energy balance in humans. Public Health Nutr. 2005;8(7a):1053-76.

6. World Health Organization. Obesity: preventing and managing the global epidemic. World Health Organization, 2000.

7. Beck KL, Mitchell S, Foskett A, et al. Dietary intake, anthropometric characteristics, and iron and vitamin D status of female adolescent ballet dancers living in New Zealand. Int J Sport Nutr Exerc Metab. 2015;25(4):335-43.doi: 10.1123/ijsnem.2014-0089. 
8. Institute of Medicine. Dietary reference intakes for vitamin $\mathrm{A}$, vitamin $\mathrm{K}$, arsenic, boron, chromium, copper, iodine, iron, manganese, molybdenum, nickel, silicon, vanadium, and zinc. 1 st ed. Washington (DC): The National Academic Press; 2001.

9. Whiting SJ, Barabash WA. Dietary Reference Intakes for the micronutrients: considerations for physical activity. Appl Physiol Nutr Metab. 2006;31(1):80-5.doi: 10.1139/h05-021.

10. DellaValle DM. Iron supplementation for female athletes: effects on iron status and performance outcomes. Curr Sports Med. 2013;12(4):234-9.doi: 10.1249/JSR.0b013e31829a6f6b.

11. World Health Organization. Iron deficiency anaemia: assessment, prevention and control: a guide for programme managers. 2001.

12. DellaValle DM, Haas JD. Iron status is associated with endurance performance and training in female rowers. Med Sci Sports Exerc. 2012;44(8):1552-9. doi: 10.1249/MSS.0b013e3182517ceb.

13. Radjen S, Radjen G, Zivotic-Vanovic M, et al. Effect of iron supplementation on maximal oxygen uptake in female athletes. Vojnosanit Pregl. 2011;68(2):130-5.

14. Dlugosz EM, Chappell MA, Meek TH, et al. Phylogenetic analysis of mammalian maximal oxygen consumption during exercise. J Exp Biol. 2013;216(Pt 24):4712-21.doi: 10.1242/jeb.088914.

15. Gabbett TJ. GPS analysis of elite women's field hockey training and competition. $J$ Strength Cond Res. 2010;24(5):1321-4.doi: 10.1519/ JSC.0b013e3181ceebbb.

16. International Nutritional Anemia Consultative Group. Measurements of iron status: a report of the International Nutritional Anemia Consultative Group (INACG). Nutrition Foundation, 1985. 0935368477.

17. Roza AM, Shizgal HM. The Harris Benedict equation reevaluated: resting energy requirements and the body cell mass. Am J Clin Nutr. 1984;40(1):168-82.

18. Leger LA, Mercier D, Gadoury C, et al. The multistage 20 metre shuttle run test for aerobic fitness. J Sports Sci. 1988;6(2):93-101.

19. Perera WDA, Jayasekera PM, Thaha SZ. Tables of food composition for use in Sri Lanka. 1st ed: World Health Foundation of Sri Lanka; 1979.

20. National Nutrient Database for Standard Reference [Internet]. 2011 [cited 1/11/2014].

21. Food and Agriculture Organization. Carbohydrates in human nutrition. Rome: FAO/WHO, 1997. Contract No.: 66.

22. Plowman SA, Smith DL. Exercise physiology for health fitness and performance. 4th ed: Lippincott Williams \& Wilkins; 2013.

23. Schoene RB, Escourrou P, Robertson HT, et al. Iron repletion decreases maximal exercise lactate concentrations in female athletes with minimal iron-deficiency anemia. J Lab Clin Med. 1983;102(2):306-12.
24. Eichner ER. Sports medicine pearls and pitfalls: anemia in athletes. Curr Sports Med. 2007;6:2-3.doi.

25. Pitsis GC, Fallon KE, Fallon SK, et al. Response of soluble transferrin receptor and iron-related parameters to iron supplementation in elite, irondepleted, nonanemic female athletes. Clin J Sport Med. 2004;14(5):300-4.

26. World Health Organization. Worldwide prevalence of anaemia 1993-2005: WHO global database on anaemia. 2008.

27. Coad J, Conlon C. Iron deficiency in women: assessment, causes and consequences. Curr Opin Clin Nutr Metab Care. 2011;14(6):625-34. doi: 10.1097/MCO.0b013e32834be6fd.

28. Hurrell R, Egli I. Iron bioavailability and dietary reference values. Am J Clin Nutr. 2010;91(5):1461S7S.doi: 10.3945/ajen.2010.28674F.

29. Goran M, Fields DA, Hunter GR, et al. Total body fat does not influence maximal aerobic capacity. Int $J$ Obes. 2000;24(7):841-8.doi. 